\title{
Damping of the Woodwind Instrument Reed Material Arundo donax L
}

\author{
Bernd Weidenfeller $^{a *}$, Osvaldo Agustín Lambrit ${ }^{b}$ Federico Guillermo Bonifacich ${ }^{b}$, Uwe Arlic ${ }^{\circledR}$, \\ Damian Gargicevich
}

\author{
${ }^{a}$ Department of Materials Science, Institute of Electrochemistry, Clausthal University of Technology, \\ 38678 Clausthal-Zellerfeld, Germany \\ ${ }^{b}$ Laboratorio de Materiales, Facultad de Ciencias Exactas, Ingeniería y Agrimensura, Universidad \\ Nacional de Rosario, Rosario, Argentina \\ 'Institute of Materials Science and Engineering, Clausthal University of Technology, 38678 \\ Clausthal-Zellerfeld, Germany
}

Received: September 04, 2017; Accepted: April 18, 2018

\begin{abstract}
The viscoelastic properties (E', G', $\tan \Phi, \delta$ ) of Arundo donax (AD) and a polypropylene-beech fiber composite (PPC) were measured from RT to $580 \mathrm{~K}$ for various frequencies and strains. $\mathrm{E}^{\prime}$ of AD varies between $5250-6250 \mathrm{MPa}$ depending on ageing at RT while $\mathrm{E}^{\prime}(\mathrm{RT})=2250 \mathrm{MPa}$ of PPC is signifcantly lower. $\mathrm{E}^{\prime}$ of the $\mathrm{AD}$ is higher than $\mathrm{E}^{\prime}$ of $\mathrm{PPC}$ in the whole investigated temperature range with the exception of $\mathrm{AD}$ after a heat treatment up to $575 \mathrm{~K}$. Damping spectra exhibit peaks around $340 \mathrm{~K}$ $(\mathrm{Q}=234 \mathrm{~kJ} / \mathrm{mol})$ and $415 \mathrm{~K}$ for the PPC related to relaxations in the crystalline part of polypropylene and the relaxation at melting temperature. For $\mathrm{AD}$ damping peaks were found at $350 \mathrm{~K}(\mathrm{Q}=320 \mathrm{~kJ} /$ $\mathrm{mol}$ ) related to the glass-rubber transition of lignin, at $420 \mathrm{~K}$ due to a reorganization in the amorphous phase of lignin, at $480 \mathrm{~K}$ related to micro-Brownian motions in the non-crystalline region of cell-wall polymers and reduction of the crystallinity of cellulose, and at $570 \mathrm{~K}$ due to the polymeric compounds of wood and/or a decomposition of lignin. The course of $E^{\prime}$ and tan $\Phi$ of AD and PPC is comparable from $20-200 \mathrm{~Hz}$, whereas $\tan \Phi$ of AD is lower than $\tan \Phi$ of PPC while E' of AD is higher than E' of PPC.
\end{abstract}

Keywords: Internal friction, Arundo donax, polymer composites, activation energy, damping.

\section{Introduction}

The giant grass Arundo donax is the most widely used material for the fabrication of the vibrating reed of woodwind instruments ${ }^{1}$. Due to health problems of some players which can be caused by Arundo donax, and due to variations in the quality of the reeds with playing duration, with regards to the growing area, and with the origin of the reed in the Arundo donax cane itself, efforts are made to replace the natural grown cane by reeds made of polymers or polymer composites to ensure constant quality. Particular, the focus lies on the simulation of the wooden structure of Arundo donax by thermoset polymers filled with parallel glass or carbon fibres ("Fiberreed"2) or by orienting the polymer backbones of thermoplastic materials by stretching the polymer ("Lègére Reeds" ${ }^{13,4}$ ). Nevertheless, these phenomenological approaches do not need to meet the physical properties of vibrating reeds necessarily as they are important for the sound and playing behaviour of woodwind instruments.

Investigations regarding chemical and static mechanical properties of Arundo donax were published in several papers $^{5-9}$. However, the viscoelastic properties of neither natural Arundo donax reeds nor of artificial reeds are well known and systematically investigated until now.
Players of woodwind instruments using Arundo donax reeds know that optimum playing conditions appear after some time of usage which might be due to the high content of water-soluble extractives, mainly of glucose, fructose, and sucrose ${ }^{10}$. Obataya et al. found a decrease of the storage modulus $\mathrm{E}^{\prime}$ and the loss tangent $(\tan \Phi)$ at $20^{\circ} \mathrm{C}$ and $60 \%$ relative humidity by extraction of the sugars. This result is an effect of the storage capability of sugars for water comparable to the increase of damping in polymers with increase of water content ${ }^{11}$. Temperature dependent measurements of the elastic modulus and loss tangent of Arundo donax show the dependence of these values on the water content ${ }^{12}$. In the temperature range between $-150^{\circ} \mathrm{C}$ and $0^{\circ} \mathrm{C}$ two damping maxima around $-110^{\circ} \mathrm{C}$ and $-50^{\circ} \mathrm{C}$ can be detected. The peak maxima are shifting with water content of Arundo donax. The low temperature damping peak was related to water adsorbed to collagen due to its activation energy of 33-59 $\mathrm{kJ} / \mathrm{mol}$ and its similarity to measurements of woods ${ }^{13,14}$. The peak at around $-50^{\circ} \mathrm{C}$ with an activation energy of $188-290 \mathrm{~kJ} /$ mol is present only in Arundo donax containing sugars. Its origin is not clarified and it is assumed that it can be related to interactive molecular motions of adsorbed water and sugar. Unfortunately in the cited papers no results of viscoelastic properties of temperatures higher than $0^{\circ} \mathrm{C}$ are shown. 
We present here our results of viscoelastic measurements of Arundo donax and a polypropylene-beech fiber composite for temperatures above room temperature. From the polypropylene-beech fiber material also a reed for an Alto saxophone was manufactured by injection molding. It was found that it was possible to play the saxophone with that reed, but according to a subjective feeling the sound of the saxophone with the polypropylen-beech fiber reed was worse compared with an Arundo donax reed.

\section{Materials and Measurement Methods}

The material for this research was Arundo donax grown in the south of France (Département Var) and delivered by company Donati SARL. The parts of the cane tubes had a length of approximately $1=140 \mathrm{~mm}$ and a diameter of approximately $\mathrm{d}=30 \mathrm{~mm}$. For mechanical measurements samples of $1=40 \mathrm{~mm}$ length, $\mathrm{w}=3 \mathrm{~mm}$ width and $\mathrm{t}=2 \mathrm{~mm}$ thickness were cut parallel to the wood fibers.

For comparison, a commercially available composite of polypropylene with approximately 75 -vol\% beech fibres (Arbofill Buche, Tecnaro GmbH, Germany) was measured. Samples were injection molded (Allrounder 320 C-600/250, Arburg, Germany) into parallelepipeds of length $1=48 \mathrm{~mm}$, width $\mathrm{w}=10 \mathrm{~mm}$ and thickness $\mathrm{t}=3 \mathrm{~mm}$.

The behaviour of the damping and the dynamic shear and elastic moduli, $\mathrm{G}^{\prime}$ and $\mathrm{E}^{\prime}$, has been studied as a function of the temperature from RT to $440 \mathrm{~K}$ (some samples up to $575 \mathrm{~K})$. The elastic modulus $\mathrm{E}^{\prime}$ was measured in forced vibration mode with a Dynamic Mechanical Analyser (Q800, TA Instruments, USA). The maximum strain was $\varepsilon=2.5 \times 10^{-3}$, and the vibration frequency was chosen in the frequency range $20 \mathrm{~Hz}-200 \mathrm{~Hz}$ corresponding to the tones E0 to G3.

Internal friction $\mathrm{Q}^{-1}$ and dynamic shear modulus $\mathrm{G}^{\prime}$ were measured in a mechanical spectrometer working in torsion in forced vibration mode at resonant frequency. Damping was determined by measuring the relative half width of the squared resonance peak for a specimen driven in forced vibration using $\mathrm{Q}^{-1}=\left(\omega_{2}-\omega_{1}\right) / \omega_{0}$. $\omega_{0}$ is the resonant frequency and $\omega_{1}$ and $\omega_{2}$ are the frequencies at which the amplitude of oscillation has fallen to $1 / \sqrt{2}$ of the maximum value.

Amplitude dependent measurements of internal friction were done at natural frequency in free decay at room temperature. Beams of $\mathrm{A}=3 \mathrm{~mm} \times 3 \mathrm{~mm}$ cross section and $1=50 \mathrm{~mm}$ length were fixed at one end and excited to resonance vibration. A decrease in the amplitude with time $t, A(t)$, of the free sample vibration was detected by a laser beam. The decrement $\delta$ was determined by a special software according to the exponential law $\mathrm{A}(\mathrm{t})=$ $\mathrm{A}_{0} \cdot \exp (-\delta \mathrm{t} / \mathrm{T})$ with the maximum amplitude $\mathrm{A}_{0}$ and the period of vibrations $\mathrm{T}$.

\section{Results and Discussion}

Figure 1 shows the dependence of the storage modulus $E^{\prime}$ and loss factor $\tan \Phi$ on the frequency for two different pieces of Arundo donax and for comparison purposes of a composite made of polypropylene and $75 \mathrm{vol} \%$ beech fibers. It can be seen that the storage modulus E' of the two Arundo donax samples are lying around $5250 \mathrm{MPa}$ and $6250 \mathrm{MPa}$ and therefore vary by $1000 \mathrm{MPa}$.

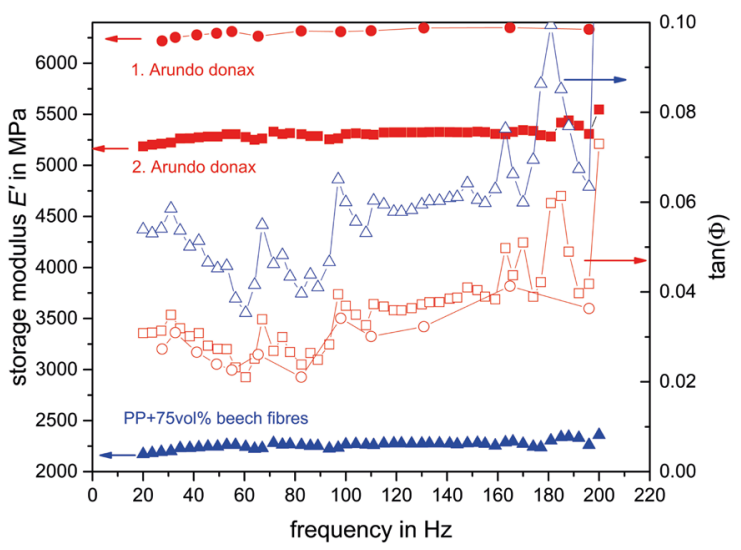

Figure 1. Dependence of the storage modulus E' and loss factor $\tan \Phi$ of two different samples made of Arundo donax and a polypropylene (PP)-beech fibre composite with $75 \mathrm{vol} \%$ beech fibers on frequency measured at room temperature.

The measured storage modulus values are comparable to reported values between 4000-7000 MPa measured by other authors who found a dependence of mechanical properties of Arundo donax on the growing conditions and on the position of the sample in the stem ${ }^{12,15}$. The storage modulus $\mathrm{E}^{\prime}$ of the commercial PP-beech fiber composite is with $2250 \mathrm{MPa}$ remarkable lower. The elastic modulus $\mathrm{E}^{\prime}$ is nearly constant in the investigated frequency range between $20 \mathrm{~Hz}$ and $200 \mathrm{~Hz}$. Likewise the frequency dependence of loss factor $\tan \Phi$ of the Arundo donax and PP composite samples are comparable in the measured frequency range.

With increasing temperature (cfFig. 2) up to approximately $\mathrm{T} \approx 350 \mathrm{~K}$ the storage modulus E' of Arundo donax decreases slowly. For higher temperatures up to $\mathrm{T} \approx 410 \mathrm{~K}$ a minor decline appears before the decline becomes steeper for higher temperatures. A similar behaviour is observed for the storage modulus of the polypropylene-beech-fiber composite. With increasing temperature up to approximately $\mathrm{T} \approx 330 \mathrm{~K}$ the storage modulus is decreased, then a minor decline appears up to $\mathrm{T} \approx 380 \mathrm{~K}$ before at higher temperatures the storage modulus decreases rapidly to zero for temperatures higher than approximately $\mathrm{T} \approx 420 \mathrm{~K}$. The temperatures at which the changes in the storage modulus appear are dependent on the chosen measurement frequencies. 

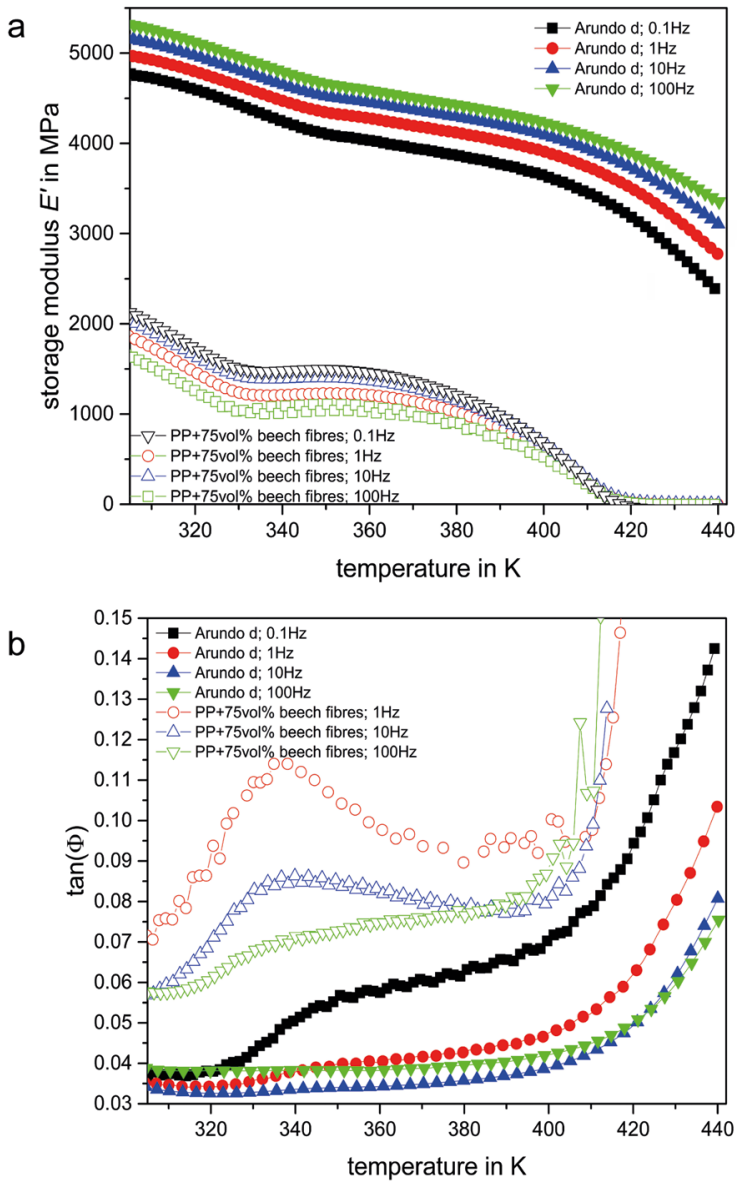

Figure 2. Temperature dependent storage modulus (a) and loss factor (b) of Arundo donax and PP-beech fiber composite.

Corresponding to the steps in the storage modulus peaks in the loss factor appear. The peak around $\mathrm{T}=340 \mathrm{~K}$ for polypropylene-beech fiber composite measured at $\mathrm{f}=1$ $\mathrm{Hz}$ can be attributed to the $\alpha^{\prime}$-peak related to relaxations in crystalline parts of the polymeric matrix ${ }^{16-18}$. The positions of the peak temperatures are dependent on the measurement frequencies and are shifted to higher temperatures with increasing vibration frequency indicating thermal activated processes. Assuming thermal activated processes the activation energies can be calculated using the Arrhenius law

$$
\tau=\tau_{0} e^{\frac{Q}{R T}}
$$

with relaxation time $\tau$, pre-exponential factor $\tau_{0}$, temperature $\mathrm{T}$, universal gas constant $\mathrm{R}$ and activation energy $\mathrm{Q}$.

At the temperature $T_{p}$ of the peak position the vibrating frequency $\mathrm{f}$ fulfills the condition $2 \pi \mathrm{f} \tau=1$ which leads to

$$
f=f_{0} e^{-\frac{Q}{R T_{p}}}
$$

with $\mathrm{f}_{0}=1 / 2 \pi \tau_{0}$. Plotting the inverse peak temperature $1 / T_{p}$ versus the logarithm of the frequency $\ln (\mathrm{f})$ enables the calculation of the activation energy from the slope of the straight line (not shown here). The peaks were fitted using the PeakFit software (V4, Jandel Scientific Software). Using this method an activation energy of $\mathrm{Q}_{\alpha, \mathrm{PP}}=234 \mathrm{~kJ} / \mathrm{mol}$ was estimated for the $\alpha$, '-relaxation of the polypropylene-beechfiber composite. This value lies within the activation energies $84-470 \mathrm{~kJ}$ depending on the grade and volume fraction of the filler previously measured for various polypropylene composites $^{17,18}$. Similarly, the activation energy for the peak around $\mathrm{T}=350 \mathrm{~K}$ in Arundo donax can be estimated to be $\mathrm{Q}_{\mathrm{AD}}=320 \mathrm{~kJ} / \mathrm{mol}$. A peak in the loss factor $\tan \varphi$ in the temperature region between $330-370 \mathrm{~K}$ was observed for various kinds of wood (eg. spruce, fir) and identified as the glass-rubber transition of lignin ${ }^{19,20}$.

The effect of two weeks of aging at room temperature on the viscoelastic behaviour of Arundo donax can be seen in Fig. 3. In a first heating cycle up to $420 \mathrm{~K}$ the elastic modulus $\left(\alpha f^{2}\right)$ is continuously decreased. In the following first cooling cycle the elastic modulus is increased with decreasing temperature and the modulus at room temperature is significantly higher than the modulus of Arundo donax before the first heating cycle. After two weeks of aging at room temperature and a new heating cycle it can be observed that the modulus is again considerably higher. Such an increase in modulus and decrease of loss factor after heating was observed previously ${ }^{21}$, and it might be due to a reorganization in the amorphous phase of lignin as it can be observed also for technical polymers ${ }^{22}$. This assumption is supported by the fact that the peak at around $\mathrm{T}=350 \mathrm{~K}$ in the loss factor measurement becomes more distinct in the heating cycle after ageing, and additionally, in the second heating cycle a new peak at approximately $420 \mathrm{~K}$ appeared. A degradation of the Arundo donax during the first heating cycle is unlikely as it was observed for Arundo donax only for temperatures above approximately $\mathrm{T} \approx 450 \mathrm{~K}^{23,24}$.

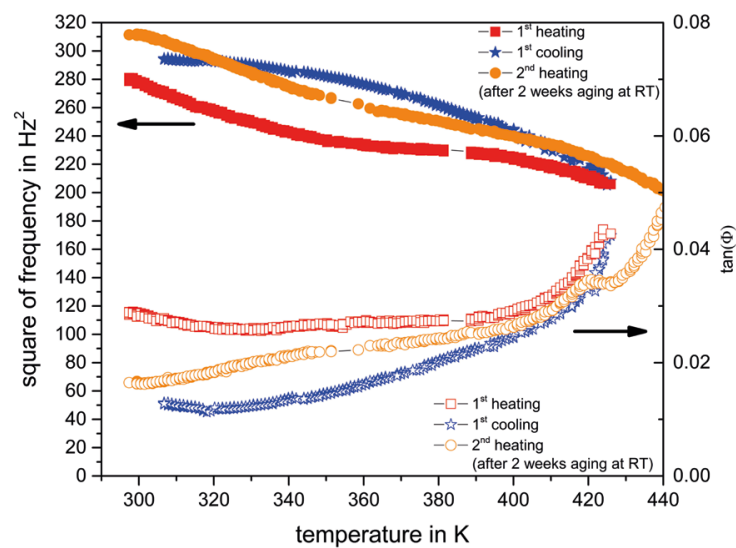

Figure 3. Measurement of the loss factor $\tan \Phi$ and elastic modulus $\left(\alpha \mathrm{f}^{2}\right)$ to show the effect of aging at room temperature on a sample of Arundo donax. 
Figure 4 shows a first heating cycle up to $\mathrm{T}=430 \mathrm{~K}$ with a behaviour of the loss factor and the elastic modulus comparable to previously shown sample. The cooling cycle again shows an increase in the modulus and a decrease of the loss factor which is again due to a re-arrangement of amorphous phase of lignin. This leads to a more distinct peak below $\mathrm{T}=400 \mathrm{~K}$ in the loss factor in a second heating cycle up to $\mathrm{T}=570 \mathrm{~K}$. Furthermore, a clear peak around $\mathrm{T}=480 \mathrm{~K}$ appears. Simultaneously the elastic modulus is significantly decreased. A relaxation peak around $\mathrm{T}=480 \mathrm{~K}$ can be found in wood and it can be related to micro-Brownian motions in the non-crystalline region of cell-wall polymers ${ }^{19,25,26}$. Furthermore, the crystallinity of cellulose is decreased in this temperature region ${ }^{27-30}$.

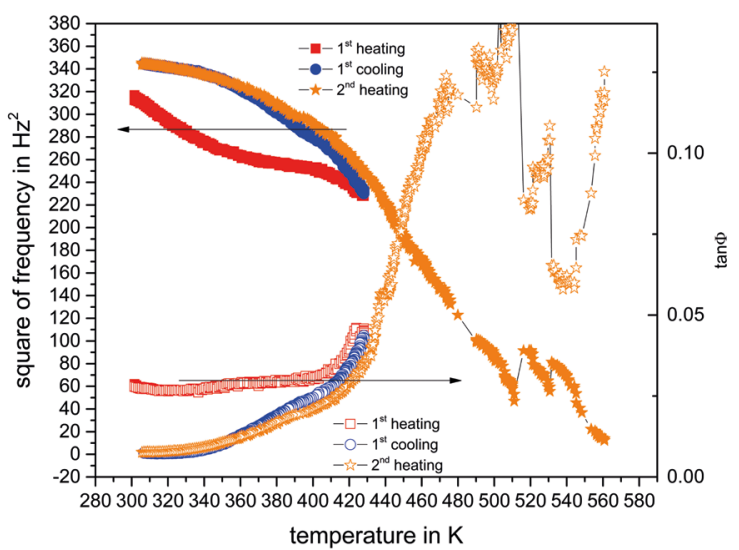

Figure 4. Measurement of the loss factor $\tan \Phi$ and elastic modulus $\left(\alpha \mathrm{f}^{2}\right)$ to show the effect of aging at room temperature on a sample of Arundo donax.

If a sample after a heating cycle up to $\mathrm{T}=570 \mathrm{~K}$ is cooled down to room temperature and then heated again up to $\mathrm{T}=575$ $\mathrm{K}$, the peaks below $\mathrm{T}=550 \mathrm{~K}$ disappear and only one peak at $\mathrm{T}=570 \mathrm{~K}$ appears. This peak is visible in Figure $5 \mathrm{~b}$ for sample Arundo d. $2 ; 2^{\text {nd }}$ heating. It corresponds to a dramatic drop of the modulus $\left(\alpha \mathrm{f}^{2}\right)$. At a temperature around $\mathrm{T}=570$ $\mathrm{K}$ the degradation under oxygen of lignin can be found for woods ${ }^{24,31}$. Furthermore, measurements of wood in a Dynamic Mechanical Thermal Analyzer using a frequency of $\mathrm{f}=10 \mathrm{~Hz}$ showed a peak around $\mathrm{T}=520 \mathrm{~K}$ which is due to the glass transition of polymeric components of the wood $\mathrm{d}^{32}$.

The damping peak around $\mathrm{T}=475 \mathrm{~K}$ related to microBrownian motions in the non-crystalline region of cell-wall polymers and reduction of the crystallinity of cellulose can be observed for all investigated Arundo donax samples but with small changes in peak temperature.

By using another Arundo donax sample with a shorter length (Arundo d. 3) to change resonance frequency it can be observed that the high temperature damping peak observed at $\mathrm{T}=480 \mathrm{~K}$ splits into two peaks around $480 \mathrm{~K}$ and $525 \mathrm{~K}$. Due to the sample geometry the $\tan \Phi$-values show high a

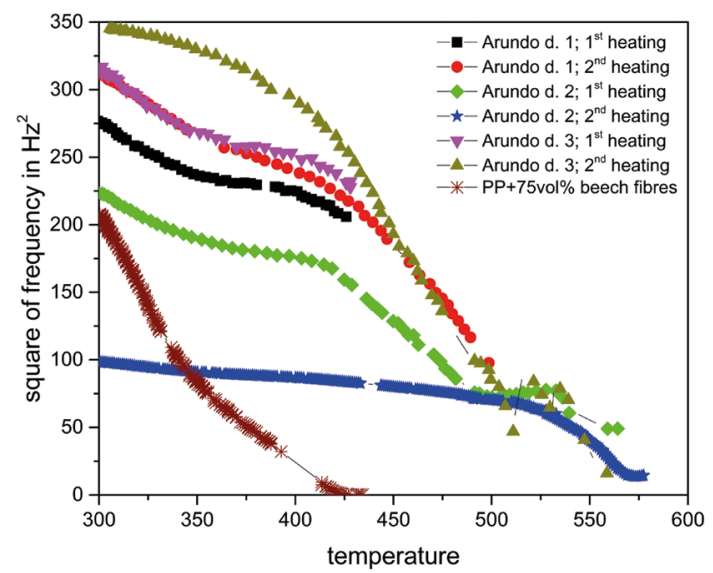

b

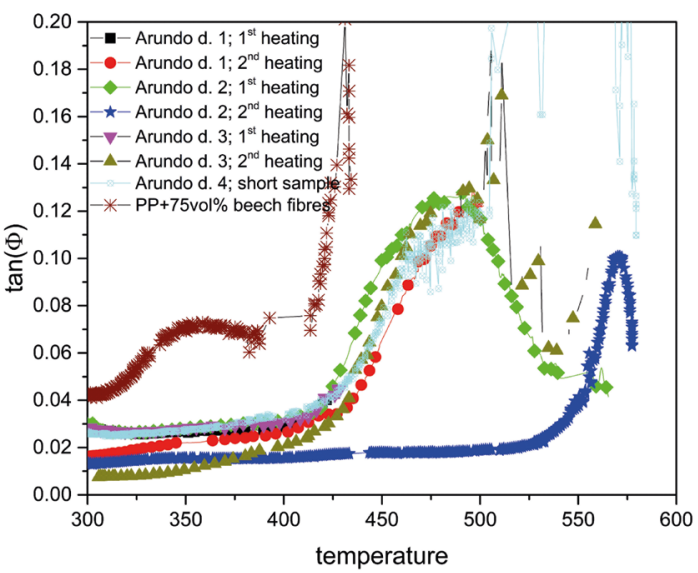

Figure 5. (a) Temperature dependent elastic modulus $\left(\alpha \mathrm{f}^{2}\right)$ for two Arundo donax samples (Arundo d. 1 and Arundo d. 3) in a first heating cycle up to $430 \mathrm{~K}$ followed by a second heating cycle up to $575 \mathrm{~K}$ and for one Arundo donax sample (Arundo d. 2) heated up to $575 \mathrm{~K}$ in a first and a second heating cycle. The elastic modulus of another shorter sample with higher $\mathrm{f}^{2}$-values is not shown in this diagram due to reasons of clarity. Furthermore, the modulus of the polypropylene beech fiber composite is shown. (b) Corresponding damping spectra of the samples including the damping of the shorter sample to indicate a possible shift of the peak temperature with frequency.

scatter. The damping peak at the higher temperature $(\mathrm{T}=525$ $\mathrm{K})$ corresponds to the above mentioned peak due to the glass transition of polymeric components of the wood.

However, the elastic modulus $\left(\alpha f^{2}\right)$ (cf Fig. 5a) shows corresponding behaviour with less scattering of measurement points. The higher modulus $\left(\alpha f^{2}\right)$ of this sample compared to the other samples is due to the changed sample geometry.

The polypropylene-beech fiber composite shows a remarkable lower storage modulus than Arundo donax which could be already seen in Figure 2a. The loss factor of the composite is clearly higher than the loss factor of Arundo donax. It is also stronger increased already at low temperatures due to relaxations in crystalline parts of the polymeric matrix and finally due to the melting of the polymer than the loss factor of the Arundo donax. 
Figure 6 shows the amplitude dependent internal friction of Arundo donax and the polypropylene-beech fiber composite. The damping of Arundo donax is slowly increased from $\delta=0.06$ to $\delta=0.10$. For low strains of $\varepsilon=3 \times 10^{-5}$ the damping of the polypropylene composite is comparable low, but it is clearly increased to $\delta=0.16$ at a strain of approximately $\varepsilon \approx 2 \times 10^{-4}$. For higher strains only a slight increase for both samples is observed. A dramatic increase of the logarithmic decrement due to changes in the material's structure (eg opening cracks, cavitation, plastic deformation) is not observed for the applied strains ${ }^{33}$.

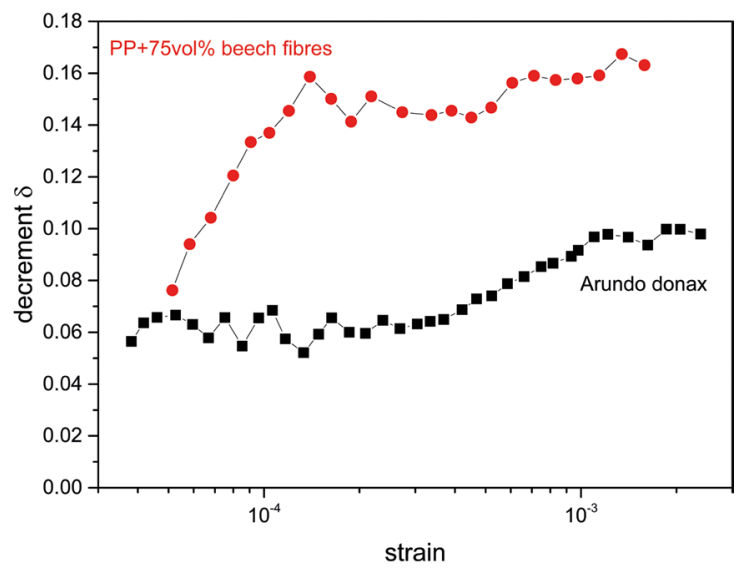

Figure 6. Amplitude dependent internal friction characterized by the logarithmic decrement $\delta$ dependent on the strain of Arundo donax and a PP-beech fiber composite at room temperature.

\section{Conclusions}

For the Arundo donax samples four damping peaks above room temperature were found, while the polypropylene beech fiber composite exhibits only one damping mechanism above room temperature and below melting temperature. While the modulus of the Arundo donax samples was considerably higher than the modulus of the composite the loss factor was significant lower. It can be assumed that these differences lead to different playing performances of natural and artificial woodwind reeds made of thermoplastic or thermoset materials. Nevertheless, further investigations are necessary for a comprehensive knowledge of the viscoelastic properties of natural reeds which enables copying of these properties into the viscoelastic properties of artificial reeds for woodwind instruments.

\section{References}

1. Lord AE Jr. Viscoelasticity of the giant reed material Arundo donax. Wood Science and Technology. 2003;37(3-4):177-188.

2. Harry Hartmann's fiberreed. The principle about fiberreed; 2014. Available from: $<$ https://fiberreed.de/en/the-idea $>$. Access in: 04/08/2017.
3. Légère Reeds Ltd. Why do they work; 2017. Available from: $<$ http://www.legere.com/why-do-they-work $>$. Access in: 04/08/2017.

4. Legere G, inventor; Legere Reeds Ltd, assignee. Oriented polymer reeds for musical instruments. United States Patent US 6087571.2000 Jul 11.

5. Perdue RE. Arundo donax - Source of musical reeds and industrial cellulose. Economic Botany. 1958;12(4):368-404.

6. Wegst UGK. Bamboo and Wood in Musical Instruments. Annual Review of Materials Research. 2008;38:323-349.

7. Spatz HC, Beismann H, Brückert F, Emanns A, Speck T. Biomechanics of the giant reed Arundo donax. Philosophical Transactions: Biological Sciences. 1997;352(1349):1-10.

8. Speck O, Spatz HC. Mechanical Properties of the Rhizome of Arundo donax L. Plant Biology. 2003;5(6):661-669.

9. Rüggeberg M, Burgert I, Speck T. Structural and mechanical design of tissue interfaces in the giant reed Arundo donax. Journal of the Royal Society Interface. 2010;7(44):499-506.

10. Obataya E, Umezawa T, Nakatsubo F, Norimoto M. The Effects of Water Soluble Extractives on the Acoustic Properties of Reed (Arundo donax L.). Holzforschung. 1999;53(1):63-67.

11. McCrum NG, Read BE, Williams G. Anelastic and Dielectric Effects in Polymeric Solids. New York: John Wiley \& Sons; 1967.

12. Obataya E, Norimoto M. Mechanical relaxation processes due to sugars in cane (Arundo donax L.). Journal of Wood Science. 1999;45(5):378-383.

13. Bernier GA, Kline DE. Dynamic Mechanical Behavior of Birch Compared with Methyl Methacrylate Impregnated. Forest Products Journal. 1968;18(4):79-82.

14. Obataya E, Yokoyama M, Norimoto M. Mechanical and dielectric relaxations of wood in a low temperature range. I. Relaxations due to methylol groups and adsorbed water. Mokuzai Gakkaishi. 1996;42:243-249. In Japanese.

15. Speck O, Spatz HC. Damped oscillations of the giant reed Arundo donax (Poaceae). American Journal of Botany. 2004;91(6):789796.

16. Cavaille JY, David L, Perez J. Relaxation phenomena in non crystalline solids: Case of polymeric materials. In: Schaller R, Fantozzi G, Gremaud G, eds. Mechanical Spectroscopy $Q^{-1}$ 2001 with Applications to Materials Science. Zurich: Trans Tech Publications; 2001. p. 500-545.

17. Weidenfeller B, Riehemann W, Lei Q. mechanical spectroscopy of polymer-magnetite composites. Materials Science and Engineering: A. 2004;370(1-2):278-283.

18. Weidenfeller B. Internal friction studies of particulate filled polypropylene. Materials Science and Engineering: A. 2006;442(1-2):371-374.

19. Jiang J, Lu J, Yan H. Dynamic viscoelastic properties of wood treated by three drying methods measured at high temperature range. Wood and Fiber Science. 2008;40(1):72-79.

20. Obataya E, Furuta Y, Gril J. Dynamic viscoelastic properties of wood acetylated with acetic anhydride solution of glucose pentaacetate. Journal of Wood Science. 2003;49(2):152-157. 
21. Zeniya N, Matsuo M, Obataya E. Changes in color and vibrational properties of wood due to accelerated ageing. In: Proceedings of $2^{\text {nd }}$ International Symposium Wood Science and Craftsmanship; 2016 Sep 20-23; Kyoto, Japan.

22. Weidenfeller B, Kirchberg S. Thermal and mechanical properties of polypropylene-iron-diamond composites. Composites Part B: Engineering. 2016;92:133-141.

23. Jeguirim M, Trouvé G. Pyrolysis characteristics and kinetics of Arundo donax using thermogravimetric analysis. Bioresource Technology. 2009;100(17):4026-4031.

24. Jeguirim M, Dorge S, Trouvé G. Thermogravimetric analysis and emission characteristics of two energy crops in air atmosphere: Arundo donax and Miscanthus giganthus. Bioresource Technology. 2010;101(2):788-793.

25. Sugiyama M, Norimoto M. Temperature dependence of dynamic viscoelasticities of chemically treated woods. Mokuzai Kakkaishi. 1996;42(11):1049-1056.

26. Sugiyama M, Obataya E, Norimoto M. Viscoelastic properties of the matrix substance of chemically treated wood. Journal of Materials Science. 1998;33(14):3505-3510.
27. Taniguchi T, Nakato K. Effects of heat treatment on the fine structure of soft wood. Bulletin of the Kyoto University Forests. 1966;38:192-199.

28. Chow SZ, Pickeles KJ. Thermal softening and degradation of wood and bark. Wood Fiber Science. 1971;3(3):166-178.

29. Schaffer EL. Effect of Pyrolytic Temperature on the Longitudinal Strength of Dry Douglas-Fir. Journal of Testing and Evaluation . 1973;1(4):310-329.

30. Moraes PD, Rogaume Y, Triboulot P. Influence of temperature on the modulus of elasticity (MOE) of Pinus sylvestris L. Holzforschung. 2004;58(2)143-147.

31. Nabi-Saheb D, Jog JP. Natural fiber polymer composites: A review. Advances in Polymer Technology. 1999;18(4):351-363.

32. Hon DNS, Ou NH. Thermoplasticization of wood. I. Benzylation of wood. Journal of Polymer Science: Part A: Polymer Chemistry. 1989;27(7):2457-2482.

33. Prevorsek DC, Kwon YD, Sharma RK. Interpretive nonlinear viscoelasticity: Dynamic properties of nylon 6 fibers. Journal of Macromolecular Science, Part B. 1977;13(4):571-595. 